\title{
RISK MANAGEMENT IMPROVEMENT DRIVERS FOR EFFECTIVE RISK-BASED DECISION-MAKING
}

\author{
DOI: 10.17261/Pressacademia.2019.1166 \\ JBEF- V.8-ISS.4-2019(5)-p.223-234
}

\author{
Fernando Vegas-Fernández ${ }^{1}$, Fernando Rodríguez López ${ }^{2}$ \\ ${ }^{1}$ Universidad Politécnica de Madrid, Civil Engineering in Construction Department, Canales y Puertos, 28043 Madrid, Spain. \\ fvegas@ciccp.es, ORCID: 0000-0003-1968-9891 \\ 2 Universidad Politécnica de Madrid, Civil Engineering in Construction Department, Canales y Puertos, 28043 Madrid, Spain. \\ Fernando.Rodriguezl@upm.es, ORCID: 0000-0002-6128-6722
}

To cite this document

Vegas-Fernández, F., Rodríguez-López, F., (2019). Risk management improvement drivers for effective risk-based decision-making. Journal of Business, Economics and Finance (JBEF), V.8(4), p.223-234

Permanent link to this document: $\underline{\text { http://doi.org/10.17261/Pressacademia.2019.1166 }}$

Copyright: Published by PressAcademia and limited licensed re-use rights only.

\begin{abstract}
Purpose - Most managers are not satisfied with the operations risk management tools they have got in their companies. This article addresses risk management enhancement within integrated risk informed decision-making.

Methodology - Three distinct and independent methods were used to analyze current practices and to find a solution: A) literature review, B) brainstorming, and C) structured interviews, achieving three lists of parameters that are integrated by using semantic technics and concept theory.

Findings - The result is a list of 66 risk assessment requirements which are going to be the success key for any new risk management system trying to fill the current gap. A new Risk Management solution is proposed fitting those requirements: The Visibility Factor method (Fv) and its risk summary method.

Conclusion - Risks should be managed in a better way and a list of key success factors and a concrete solution are provided to do it.
\end{abstract}

Keywords: Risk analysis, risk management, overall risk, methodology, risk system requirements.

JEL Codes: C63, D81, D83

\section{INTRODUCTION}

New articles arise every year proposing new methods, algorithms, and studies related to risk management; and new articles also talking about the lack of academic research, risk management models and systematization (Sanchez-Cazorla et al.; Rodney et al.; Zio; Mantovani et al.). Companies are reluctant to accept innovations and typically continue to use their old methods which frequently rely on intuition and subjective evaluations, sometimes biased because of short-term approaches (Serpella et al.; Bello and Odusami). The lack of quantitative methodologies that are easy-to-use, universally applicable, and yield a quantitative value for the overall risk could be the root of this problem.

Risk management is frequently intended for compliance and, for that reason, operations managers do not have efficient risk systems to make risk-based decisions. Current international projects are highly complex (Mishra and Mishra; Meulbroek; Institution of Civil Engineers and Institute and Faculty of Actuaries) and it makes it necessary to prioritize risks and seek the most effective way to inform boards of directors (AMRAE; ANRA; CEB Risk Management Leadership Council; EcoDa/IFC; EY; Hoyt and Liebenberg; International Organization for Standardization (ISO), "Risk Management - Risk Assessment Techniques"; Zurich Insurance Group). Project risk reports are usually very long, and they lack a simple summary showing what the project overall risk is. The information about risks has to be simple (Cretu et al.; International Organization for Standardization (ISO), "Risk Management - Guidelines."; Tsiga et al.) and it should be possible to express the overall risk of a scenario with its overall impact and likelihood and with its overall risk rate to help decision-makers to understand the overall risk situation (Tarantino-Curseri; Okan et al.).

\section{LITERATURE REVIEW}

When studying the articles published, several sources were considered (Web of Science, Scopus, Science Direct, Research Gate ASCE, Willey, and Google Scholar), reviewing more than 1,700 articles, theses, and books, of which 272 were used. 
The articles studied stress the need to use risk indicators (Hamid and Kehinde; Renault and Agumba; Tanner and Hingorani; Tóth and Sebestyén) and overall ratings for decision-making (Murakami et al.). Many works present overall risk indicators devised for very specific scenarios (Orojloo et al.; Samantra et al., "Fuzzy Based Risk Assessment Module for Metropolitan Construction Project: An Empirical Study"; Shen et al.; West et al.); whereas others present methodologies that are probabilistic, fuzzy and multivariable (Cheng and Lu; Jung et al.); others apply neuronal networks (ANN) and multiple regression (Lam and Siwingwa; Lhee). Other works bring to light a lack of literature in complex scenarios and the difficulty that firms have when it comes to applying the sophisticated methods of scientific literature (Bromiley et al.; Deng and Smyth; Serpella et al.).

The most frequently used methodologies identify the risks and assess their impact and probability (or any other additional indicator) using Likert Scales (Likert). This qualitative assessment often turns into a semi-quantitative assessment, considering the product of the impact by its probability, hereinafter Risk Factor Fr (Alcocer-Yamanaka et al.). The value Fr makes it possible the comparison of a variety of risks among themselves. However, it is not very intuitive and has drawbacks owing to its lack of linearity and to the fact that it is the mean of a probabilistic distribution (Vegas-Fernández and Rodríguez-López). The sum total of the values of $\mathrm{Fr}$ for all the events analyzed (hereinafter, sum of products of probability times impact, SPTI) is considered the expected value of the project risk (Raftery), and it can either be regarded as an absolute value that measures the overall risk level, or it can be divided by the number of risk events to obtain the average Fr.

This practice is widespread (Zou et al.; Van Niekerk and Bekker; Rodney et al.; Carpio de los Pinos and González García) but it corresponds to the average value expected for a supposed Normal distribution of the overall risk value, which would require the applicability of the Central Limit Theorem (Raftery; Diekmann; Amade et al.); However, this theorem is not applicable to current projects because they do not fulfill the basic premises required by the theorem: a large number of independent (not correlated) risk events $(>500)$ with no one component which contributes significantly (no Pareto effect) to the sum (Schuyler). As a result, the SPTI value is not suitable for estimating overall project risk or project risk cost (VegasFernández and Rodríguez-López).

\section{DATA AND METHODOLOGY}

The aim of this study is to define the basic parameters to improve risk management within the integrated risk informed decision-making process. The result, a list with 66 ranked parameters, will help new risk management system definition to be successful.

A new indicator and a new method for estimating overall risk are presented as a possible response to the improvement parameters identified. This new system is simple and effective and it is intended to remove the traditional barriers that separate academic publications from customary practice (Taroun).

To make it consistent with the approaches of Aven (Aven) the research undertaken gives precedence to professional experience with international projects and the studying and reviewing of methods, theories, principles, and frameworks of application. With a view to this, 3 different techniques have been chosen among the techniques ISO 31010 proposes to identify risks and to assess solutions (International Organization for Standardization (ISO), "Risk Management - Risk Assessment Techniques"). In this study, they were used to obtain ranked lists of improvement ideas, which are integrated later on into a single ranked list. Integrating these techniques allows a final, reliable conclusion to be obtained (Fernández Sánchez; Hruškovič; Leceta Ostolaza; Pérez Soriano). These techniques are:

1, reviewing the available scientific literature. ISO 31010 and most authors use this information source to obtain qualitative information, but this study makes a deep study applying a method to obtain a quantitative outcome.

2 , brainstorming. A means of collecting a broad set of ideas and evaluation, ranking them by a team. Brainstorming involves stimulating and encouraging free-flowing conversation amongst a group of knowledgeable people.

3, structured interviews. Individual interviewees are asked a set of prepared questions from a prompting sheet which encourages the interviewee to view a situation from a different perspective.

ISO 31010 proposes these techniques among others to identify risks and to assess solutions. In this study, they are used to obtain a ranked list of improvement ideas, which are integrated later on into a single ranked list.

\section{EMPIRICAL FINDINGS}

\subsection{Literature Review}

In the study conducted into the 272 references selected, the analysis of syntagmas (clauses or words) is used to identify the concepts sought, and their appearance is weighted using weights that consider the document type (standard or regulation, doctoral thesis, book, indexed journal, lecture source, unindexed journal, master thesis, website run by a renowned 
organization and standard website). The date and their scope have also been considered by adding +0.5 in documents after 2009 and by subtracting 0.5 when they are intended for a specific activity or a particular country.

By adding for each concept the number of references that contains it times the reference weight, the outcome is a value that indicates the relevance of that concept in the references selected. The maximum value is 857 and corresponds to "decision-making". In order to check a possible Pareto behavior, an accumulated percentage is also obtained for each concept by dividing the sum of the accumulated values in a ranked list by the sum of all the values.

Figure 1 displays the distinct weights assigned to each type of document.

\section{Figure 1: Publication Weights}

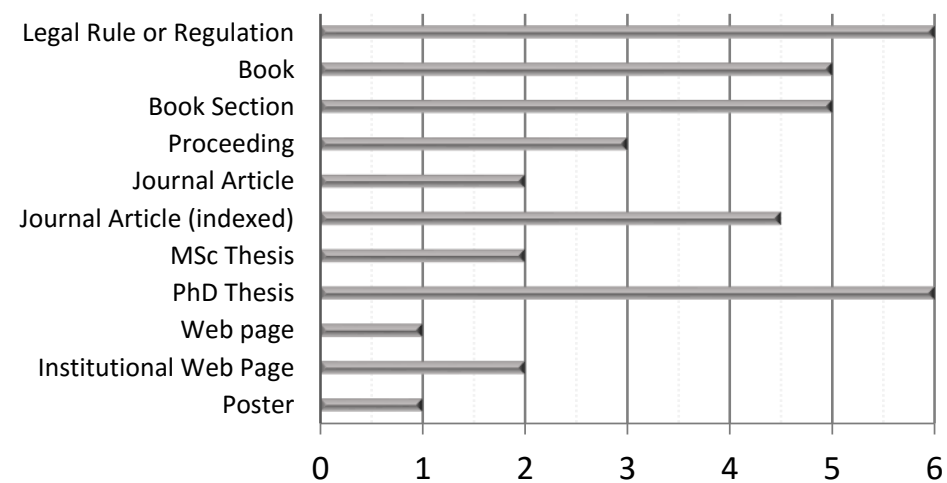

The structured list of the characteristics studied is shown next, with their punctuation (Table 1). It is ranked according to the values, and the accumulated percentage is the sum of the own and previous concept values divided by the sum of values.

Table 1: Summary of Concepts Analyzed When Reviewing the Literature

\begin{tabular}{|c|c|c|}
\hline Concept & Value & $\%$ accumulated \\
\hline Decision-making & 857 & $8 \%$ \\
\hline Importance & 665 & $14 \%$ \\
\hline Uncertainty & 556 & $20 \%$ \\
\hline Subjectivity & 549 & $25 \%$ \\
\hline Quantify & 533 & $30 \%$ \\
\hline System & 430 & $38 \%$ \\
\hline Impact + Probability & 420 & $42 \%$ \\
\hline Key Risk Indicator (KRI) & 415 & $46 \%$ \\
\hline Final rating & 379 & $50 \%$ \\
\hline Overrun & 356 & $53 \%$ \\
\hline Bias & 352 & $56 \%$ \\
\hline ERM deficiencies & 329 & $59 \%$ \\
\hline Probabilistic & 322 & $62 \%$ \\
\hline Compare & 288 & $65 \%$ \\
\hline Contingency & 279 & $68 \%$ \\
\hline Correlation & 278 & $70 \%$ \\
\hline Strategy (integration) & 259 & $73 \%$ \\
\hline Overall risk & 226 & $75 \%$ \\
\hline Mitigation & 219 & $77 \%$ \\
\hline Attitude & 199 & $79 \%$ \\
\hline $\mathrm{Fr}$ & 179 & $81 \%$ \\
\hline Expected Value & 169 & $82 \%$ \\
\hline I / P Map & 153 & $84 \%$ \\
\hline Fuzzy & 143 & $85 \%$ \\
\hline Conf. level & 136 & $86 \%$ \\
\hline Simplicity & 134 & $88 \%$ \\
\hline Clear reports & 134 & $89 \%$ \\
\hline Evolution & 131 & $90 \%$ \\
\hline Risk maps & 130 & $91 \%$ \\
\hline
\end{tabular}




\begin{tabular}{lrr} 
Risk appetite & 112 & $92 \%$ \\
Linear / non-linear scale & 109 & $93 \%$ \\
SPTI & 104 & $94 \%$ \\
Monte Carlo & 91 & $95 \%$ \\
Pareto & 78 & $96 \%$ \\
Operations (integration) & 78 & $97 \%$ \\
More indicators & 73 & $97 \%$ \\
PERT & 72 & $98 \%$ \\
ANN & 64 & $99 \%$ \\
Multiple regression & 58 & $99 \%$ \\
Silos & 46 & $100 \%$ \\
Red lines & 32 & $100 \%$ \\
3 lines of defense & 17 & $100 \%$ \\
\hline
\end{tabular}

\subsection{Brainstorm}

The brainstorm session was held in Madrid at the Escuela Técnica Superior de Ingenieros de Caminos, Canales y Puertos, and the subject dealt with was "Difficulties experienced in the everyday practice of project risk assessment and when informing about the overall risk situation, aimed at effective decision-making". The conclusions were that risk management had to be aligned with the company's strategy, that a systematic and objective method is required in order to quantify the risks, backed up by a system that collects information from the operational units, that simple and easy-to-understand indicators are needed that make it possible to compare risks and scenarios with each other and with the risk appetite and red lines, and that the system has to be automatic and cannot be manipulated.

Each idea was given a score considering the number of attendees supporting that idea and the number of times that concept was repeated. The higher score was 36 , assigned to "Objectivity".

The analysis of the ideas, homogenized and rated according to the number of participants in agreement, is summarized in Error! Reference source not found.. In order to check a possible Pareto behavior, an accumulated percentage is also obtained for each concept by dividing the sum of the accumulated values in the ranked list by the sum of all the values.

Table 2: Summary of the Concepts Put Forward in the Brainstorm

\begin{tabular}{lrc}
\hline Concept & Value & \% accumulated \\
\hline Objectivity & 36 & $11 \%$ \\
Decision-making & 36 & $21 \%$ \\
Uniformity & 32 & $31 \%$ \\
Analytical system & 24 & $38 \%$ \\
Risk indicator (KRI) & 24 & $45 \%$ \\
Non-quantifiable risks & 23 & $52 \%$ \\
Comparisons & 16 & $56 \%$ \\
Clarify & 16 & $61 \%$ \\
Evolution & 16 & $66 \%$ \\
Risk appetite & 15 & $70 \%$ \\
Cost & 15 & $75 \%$ \\
Integration with strategy & 14 & $79 \%$ \\
Simplicity & 14 & $83 \%$ \\
Alternative qualification & 14 & $87 \%$ \\
Structured system & 12 & $91 \%$ \\
Qualitative impact and probability & 12 & $94 \%$ \\
Limit scope & 7 & $96 \%$ \\
Not making mistakes & 4 & $97 \%$ \\
Uncertainty & 4 & $99 \%$ \\
Operational personnel & 2 & $99 \%$ \\
Forecasting & 1 & $99 \%$ \\
Reports & 1 & $100 \%$ \\
Multiple variables & 1 & $100 \%$ \\
\hline
\end{tabular}

\subsection{Structured Interviews}

The interviews were held separately with 21 professionals from different industries (most of them from the construction sector), using a complex questionnaire structured. The findings indicated the need to obtain a numerical result for the 
overall risk for a scenario and for each risk matrix, the allocation of impact and probability using a Likert scale, and the use of linear scales to assess the interpretation.

A list of 41 concepts was proposed to the interviewees, asking them to rate each concept from 0 to 3 , being 3 the higher relevance. The first interviews revealed the need to enlarge the list of concepts, and the result was a final list with 50 concepts.

The maximum obtained value was 63 and corresponds to "Qualitative rating of the overall risk level for the project". In order to check a possible Pareto behavior, an accumulated percentage is also obtained for each concept by dividing the sum of the accumulated values in a ranked list by the sum of all the values.

The structured list of the concepts rated is shown below (Error! Reference source not found.).

Table 3: Summary of Concepts Analyzed at the Interviews Conducted

\begin{tabular}{|c|c|c|}
\hline Concept & Value & $\%$ accumulated \\
\hline Qualitative rating of the overall risk level for the project & 63 & $3 \%$ \\
\hline Definition of red lines & 63 & $5 \%$ \\
\hline Use of a computerized system & 63 & $8 \%$ \\
\hline Impact and probability values expressed by scales & 63 & $10 \%$ \\
\hline A number must be obtained to express the result of the project risk & 63 & $13 \%$ \\
\hline Qualitative rating for each risk & 62 & $15 \%$ \\
\hline Allocation of the impact and probability for each risk & 62 & $18 \%$ \\
\hline Quantitative rating of the overall risk level for the project & 62 & $20 \%$ \\
\hline Possibility of adding specific risks for each project & 61 & $23 \%$ \\
\hline Defining the risk appetite & 60 & $25 \%$ \\
\hline Indicating the risk type (cost, deadline, quality, reputation, safety, etc.) & 60 & $27 \%$ \\
\hline A number must be obtained for each matrix & 60 & $30 \%$ \\
\hline Linear scales to rate and interpret risks & 60 & $32 \%$ \\
\hline Quantitative rating for each risk (risk level) & 59 & $35 \%$ \\
\hline The effects of the actions of reducing or mitigating proposed must be rated & 59 & $37 \%$ \\
\hline Monitoring risk evolution & 58 & $39 \%$ \\
\hline A number must be obtained for each risk assessed & 58 & $42 \%$ \\
\hline A distinction must be made between the possible, probable and mitigated cost & 58 & $44 \%$ \\
\hline The total cost envisaged is the sum of the products of cost $x$ probability & 58 & $46 \%$ \\
\hline The red line concept (exclusive risk condition) has to be considered & 58 & $49 \%$ \\
\hline Organizing the risks into chapters in the matrices & 57 & $51 \%$ \\
\hline A separate rating for each type of risk & 57 & $53 \%$ \\
\hline The cost associated with the risk must be calculated & 57 & $55 \%$ \\
\hline Use of a template to assess risks & 56 & $58 \%$ \\
\hline Structuring the risks identified (by matrices or similar) & 56 & $60 \%$ \\
\hline Need for greater objectivity in the ratings & 56 & $62 \%$ \\
\hline Use of matrices to organize risks & 55 & $64 \%$ \\
\hline Use of weighting to distinguish between the importance of the various risks & 55 & $67 \%$ \\
\hline The mitigation effect must be estimated separately for the impact and probability & 55 & $69 \%$ \\
\hline Breakdown structure of the risks & 54 & $71 \%$ \\
\hline Vision of development in time & 53 & $73 \%$ \\
\hline Decision-making integration & 53 & $75 \%$ \\
\hline A number result must be obtained for each risk group (chapters) & 49 & $77 \%$ \\
\hline Consistency between cost mitigation and the estimated effect of the mitigating measures & 49 & $79 \%$ \\
\hline The weighting of the risks must refer to the organizing unit where the risk is & 47 & $81 \%$ \\
\hline Use of one single risk questionnaire for all the projects & 46 & $83 \%$ \\
\hline Quantitative rating of the overall risk for each matrix (risk level) & 45 & $85 \%$ \\
\hline Rating the overall impact and probability on the project & 45 & $87 \%$ \\
\hline The cost of the mitigating measure must be broken down & 45 & $88 \%$ \\
\hline Each organizing unit must have its own weight & 44 & $90 \%$ \\
\hline Quantitative rating of the risk level of groups of projects & 42 & $92 \%$ \\
\hline Qualitative rating of the overall risk for each matrix & 37 & $93 \%$ \\
\hline Potential for adding risks not included on the template & 34 & $95 \%$ \\
\hline Rating the impact and overall probability of each matrix & 34 & $96 \%$ \\
\hline Use of graphs (heat maps) & 31 & $97 \%$ \\
\hline Use of a questionnaire with predetermined questions and answers to be selected & 30 & $98 \%$ \\
\hline
\end{tabular}


Use of probabilistic methods, such as Monte Carlo, to calculate the total cost

Use of other indicators (speed, vulnerability, etc.,)

$\begin{array}{rr}13 & 99 \% \\ 10 & 99 \% \\ 9 & 100 \% \\ 6 & 100 \%\end{array}$

Use of Monte Carlo

\subsection{Integration}

The analysis of the previous results shows that the Pareto effect is not present. So the idea of selecting just the top $20 \%$ concepts of each list is not suitable and all of them have been considered initially.

In order to integrate the findings, they were given a weight of 1.1 for the literature review, a weight of 1.0 for the brainstorm and a weight of 1.2 for the interview results. Priority is given to the interviews because the respondents were all practitioners, and much more time was devoted to this than to the brainstorm. An intermediate weight was given to the literature despite its great academic value, because of the distance between the publications and customary practice (Thamhain; Taroun; Deng and Smyth).

The different way the concepts were formulated for each one of these three study sources, a consequence of their different origin, makes it necessary to conduct a semantic analysis of the concepts announced in each one, with a view to establishing the equivalences that enable the findings to be integrated.

One single list of homogenized semantic concepts was then obtained, whose rating is the sum total, for each concept, of the scores for the semantically similar concepts in each source, using the previously defined weights. The list contains 66 results or basic improvement parameters, and it is displayed in Error! Reference source not found.. The accumulated percentage is showed one more time to confirm that the Pareto effect is not present even in the integrated results.

Table 4: Basic Improvement Parameters

\begin{tabular}{|c|c|c|c|}
\hline No & Parameter & Value & $\%$ accumulated \\
\hline 1 & Decision-making & 351 & $4 \%$ \\
\hline 2 & Quantitative project rating & 336 & $8 \%$ \\
\hline 3 & Need to be objective & 307 & $11 \%$ \\
\hline 4 & Need to quantify (risks, groups, and matrices) & 297 & $15 \%$ \\
\hline 5 & Use of a risk indicator (KRI) & 293 & $18 \%$ \\
\hline 6 & Computerized system & 285 & $21 \%$ \\
\hline 7 & Qualitative project rating & 270 & $24 \%$ \\
\hline 8 & Uniformity & 269 & $27 \%$ \\
\hline 9 & Use of templates for risk assessment & 267 & $30 \%$ \\
\hline 10 & Importance of the risk analysis & 267 & $33 \%$ \\
\hline 11 & Qualitative rating for each risk & 256 & $36 \%$ \\
\hline 12 & One single risk questionnaire for all the projects & 252 & $39 \%$ \\
\hline 13 & Global impact and probability of the project & 246 & $42 \%$ \\
\hline 14 & Comparisons & 237 & $44 \%$ \\
\hline 15 & Allocation of the impact and probability for each risk & 231 & $47 \%$ \\
\hline 16 & Potential, probable and mitigated cost & 227 & $49 \%$ \\
\hline 17 & Calculating the cost of the risks & 227 & $52 \%$ \\
\hline 18 & Quantifying risk for a group of projects & 220 & $54 \%$ \\
\hline 19 & Integration with strategy & 217 & $57 \%$ \\
\hline 20 & Consideration given to different risk types & 203 & $59 \%$ \\
\hline 21 & Risk appetite and red lines & 192 & $61 \%$ \\
\hline 22 & Use of linear scales for Impact and Probability & 187 & $63 \%$ \\
\hline 23 & Structured risk system & 182 & $65 \%$ \\
\hline 24 & Cost - Risk as summed up SPTI & 181 & $67 \%$ \\
\hline 25 & Simplicity & 180 & $69 \%$ \\
\hline 26 & Risk evolution & 180 & $71 \%$ \\
\hline 27 & Rating for mitigation effects & 154 & $73 \%$ \\
\hline 28 & Use of graphs (heat maps) & 151 & $75 \%$ \\
\hline 29 & Expected value of I $\times \mathrm{P}$ & 143 & $76 \%$ \\
\hline 30 & Uncertainty & 125 & $78 \%$ \\
\hline 31 & Cost overrun & 120 & $79 \%$ \\
\hline 32 & System open to new risks & 118 & $81 \%$ \\
\hline 33 & A separate rating for each type of risk & 113 & $82 \%$ \\
\hline 34 & Use of weighting for risks & 112 & $83 \%$ \\
\hline
\end{tabular}


35 Independent mitigation for impact and probability

36 Mitigated cost consistent with mitigation

37 Weight of risks relative to their organizing unit

38 Breakdown of mitigation cost

39 Each organizing unit must have its own weight

40 Considering probabilistic methods

41 Not making mistakes

42 Clarification

43 Qualitative rating of the overall risk for each matrix

44 Rating the impact and overall probability of each matrix

45 Non-quantifiable risks

46 Questionnaire assessment with predetermined questions and answers

47 ERM deficiencies

48 Alternative qualification

49 Use of an objective system (closed)

50 Correlation between risks

51 Use of additional indicators

52 Influence of overall risks

53 Attitude

54 Use of Monte Carlo

55 Clear reports

56 Limit the scope

57 Forecasting

58 Fuzzy methods

59 Confidence level

60 Integration with operations

61 PERT

62 Pareto

63 Neural networks (ANN)

64 Multiple regression

65 Presence of silos

663 lines of defense

\begin{tabular}{rr}
108 & $84 \%$ \\
107 & $86 \%$ \\
94 & $87 \%$ \\
91 & $88 \%$ \\
88 & $89 \%$ \\
84 & $90 \%$ \\
82 & $90 \%$ \\
81 & $91 \%$ \\
81 & $92 \%$ \\
75 & $93 \%$ \\
70 & $94 \%$ \\
67 & $95 \%$ \\
60 & $95 \%$ \\
45 & $96 \%$ \\
37 & $96 \%$ \\
36 & $97 \%$ \\
33 & $97 \%$ \\
30 & $97 \%$ \\
30 & $98 \%$ \\
29 & $98 \%$ \\
27 & $98 \%$ \\
25 & $99 \%$ \\
21 & $99 \%$ \\
21 & $99 \%$ \\
20 & $99 \%$ \\
17 & $99 \%$ \\
10 & $100 \%$ \\
10 & $100 \%$ \\
9 & $100 \%$ \\
8 & $100 \%$ \\
6 & $100 \%$ \\
3 & $100 \%$ \\
\hline & \\
\hline 1 &
\end{tabular}

\subsection{Discussing the Findings}

The findings have been presented for the proposals for improvement of the risk management function in complex projects, both individually for each one of the study methods followed, but also for the view resulting from their integration. These findings are not consistent with the forecast of the Pareto rule, according to which $20 \%$ of the proposals (13) would attain $80 \%$ of the desired satisfaction (Leceta Ostolaza; Pérez Soriano), but $50 \%$ of them would make up $80 \%$ of the rating made.

An analysis of the 10 most important improvement parameters is significant when it comes to understanding the scope of the findings and showing that they are consistent with each other.

The best-rated aspect is "decision-making" and it reveals the importance of the risk management role in companies.

The second best-rated aspect, "Quantitative project rating", is a demand that has stood out in each of the three study sources, and it comes from lack of knowledge about the overall risk level of the projects when, for the analysis, a large number of risk events have been pinpointed (Institution of Civil Engineers and Institute and Faculty of Actuaries).

The "Need for objectivity" underlines the aforementioned parameters and demands a system that makes it possible to reduce subjectivity, pre-judgments and, even, decisions based only on experience.

The "Need to quantify (risks, groups, and matrices)" requires an analytical quantitative system to be able to conduct a detailed study of the risk situation affecting the project.

The fifth requirement, "Use of a risk indicator (KRI)", calls for a general indicator applicable to any type of risk and project, and demonstrates the lack of a general indicator applicable to all cases, essential for the analytical studies and the comparisons required by a decision-making system.

A "Computerized system" is a basic requirement for achieving uniformity, reliability and an analytical view of risk management. 
The seventh improvement parameter is "Qualitative project rating", and its presence among the most important is explained by the difficulties involved in quantifying many of the risks when using current methods and by the need to have a vision, even if it is only qualitative, of the risk level for the project as a whole.

The eighth and ninth requirements ask for "Uniformity" to standardize and compare situations, and for "Use of templates for risk assessment" to make it easier to work in a standardized way.

The tenth parameter "Importance of the risk analysis", rather than being interpreted as a guideline, has to be regarded as a call to attention with respect to the role that risk assessment ought to play in companies.

These 10 requirements, together with the remaining ones, are the improvement parameters that would make it possible to define a risk system to fulfill the needs explained, providing solutions to the current deficiencies.

The study concerning the parameters at the tail end showed that the proposals put forward for using the Fuzzy methods, the Neural Networks (ANN), multiple regression and forecasting were not generally accepted. It is also important to note that the concept of the 3 lines of defense (The Institute of Internal Auditors) received the poorest rating and is not associated with the strategy or the importance of risk management.

The fact that little importance is attached to using the Monte Carlo simulation (position 50) and considering the correlation between risk events (Position 51) also stands out. These parameters are interrelated, given that good modeling of the correlation is essential if the Monte Carlo method is to yield valid results (Rezaie et al.; Touran and Wiser).

SPTI is ranked $26^{\text {th }}$ in spite of yielding misleading values, mainly because the respondents to the questions in the interviews were not aware of the problems its use implies (see section "Current situation"). The use of Fr stands out too, in $29^{\text {th }}$ position, for the same reasons.

Mantovani et al., 2014 was talking about the need to innovate rating methodologies. Many other authors claim for risk management improvements within integrated risk informed decision-making (Venkatraman and Ramasamy; Samantra et al., "A Risk-Based Decision Support Framework for Selection of Appropriate Safety Measure System for Underground Coal Mines"; Bouayed; Hamid and Kehinde). This article defines key improvement factors that will ensure that practitioners will have the risk management system they need.

\subsection{The Visibility Factor}

An example of the application of these findings is the Visibility Factor method (Vegas-Fernández, "Sistema de Información de Riesgos: Factor de Visibilidad."; Vegas-Fernández and Rodríguez-López). Its design is the consequence of considering the proposed improvement parameters; it is an innovative solution that is easy to implement and provides a new risk indicator (Fv) and a method for summarizing risk events that allow for the quantitative and analytical processing of the basic impact and probability data (Vegas-Fernández, "Factor de Visibilidad. Nuevo Indicador Para La Evaluación Cuantitativa de Riesgos").

The Visibility Factor (Fv) is a linear indicator from 0 to 100 that uses the existing impact and probability definitions made using Likert scales to obtain an automatic value for the risk level. The method incorporates a risk summary system that enables the user to obtain a significant summary for any set of risks of any type expressed in terms of its impact, probability, and Fv; this calculation can be recursive, which makes it possible to obtain summaries at a higher level such as matrices, projects, countries, divisions or companies.

The suitability of the Fv method has been checked by being actually implemented in a construction company where it has been proved its applicability, versatility, and effectiveness when compared to traditional systems. It enables its users to control the risk involved in all the projects at the tendering phase, to define the risk appetite, and to incorporate the red lines definition into the system. It also makes possible to break down the risks as much as is thought necessary (Institution of Civil Engineers and Institute and Faculty of Actuaries) and to obtain a homogenized system that can be applied to all the projects, and that is more objective and enlargeable, with analytical capacities.

This system was presented as a project at the Project Management Institute Conference held in Valencia in 2015 (VegasFernández, "Gestión de Riesgos.") and has been successfully implemented in a multinational construction company with headquarters in Spain. This implementation enabled its users to control the risk involved in all the projects at the tendering phase, to define the risk appetite, and to incorporate the red lines definition into the system (Vegas-Fernández, "Sistema de Información de Riesgos: Factor de Visibilidad."). Its simplicity also enables it to be easily programmed on spreadsheets so it can be incorporated into risk assessment templates at a very low cost.

Adopting this solution enables the user to break down the risks as much as is thought necessary (Institution of Civil Engineers and Institute and Faculty of Actuaries) to obtain a homogenized system that can be applied to all the projects, and this system is more objective and enlargeable, with analytical capacities. 
The summarizing capability and the compliance with parameter \#13 "Global impact and probability of the project" makes it possible to build risk maps such as figure 2, where the project risk is summarized by countries and the overall ("Total") risk is identified with its own impact and likelihood (Figure 2).

\section{Figure 2. Example Showing How the Fv Method is Applied}

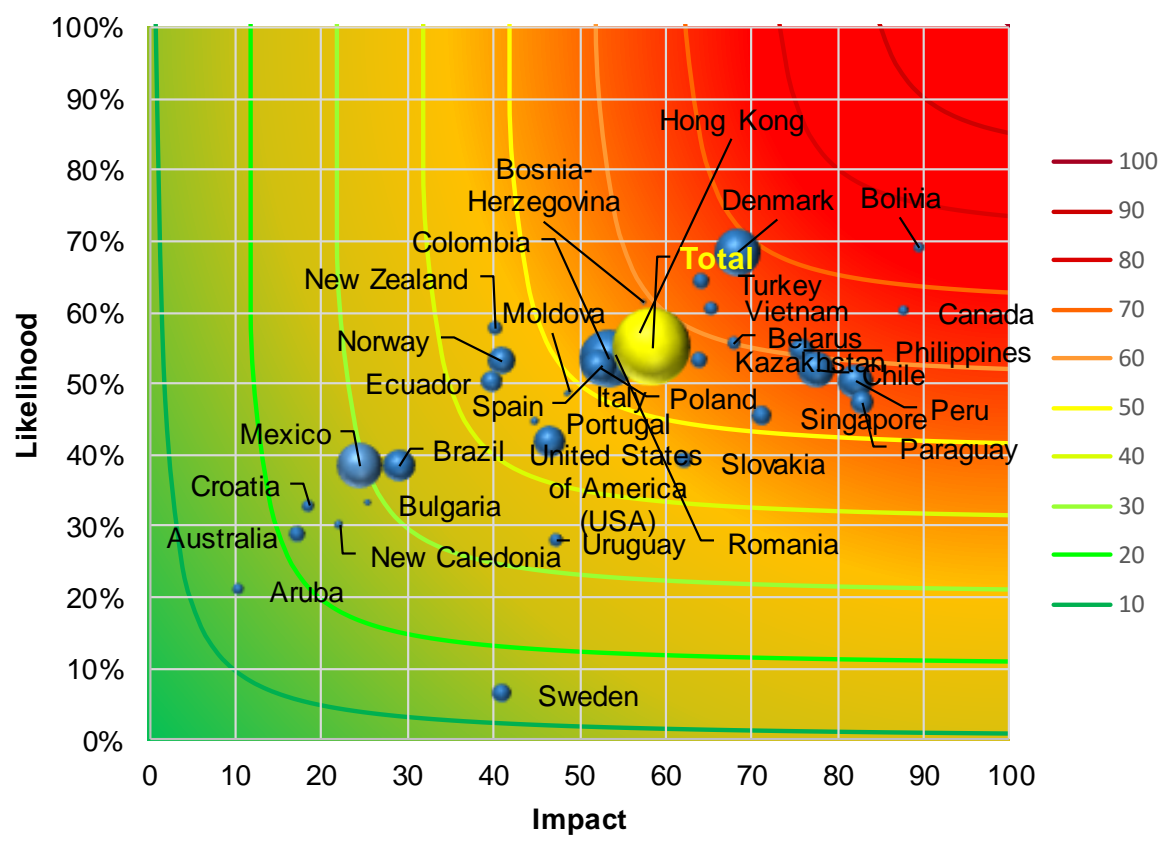

\section{CONCLUSION}

This article provides highly significant guidelines for improving risk management, based upon thorough research that has taken into account the academic literature and the work of risk managers, and proposes a specific solution that meets the needs considered.

Three independent lines of research were used yielding a single rated list with 66 basic improvement parameters.

The 10 main parameters have been analyzed in detail because these are representative of the whole to understand the main guidelines for taking action. This information is important when it comes to devising any new indicator or system aimed at achieving the desired improvement.

A practical example has been given showing a new risk management system that has been designed by following the main parameters of the list and it is being used in a construction company.

Literature and practitioners claim for better and more useful tools for risk management daily practice. Companies are frequently not up-to-date with the latest methodologies and do not possess the skills necessary to apply them. For that reason, practitioners ask for simple and effective solutions. This article presents improvement drivers to succeed in developing new risk management solutions that meet practitioners' needs.

\section{REFERENCES}

Alcocer-Yamanaka, Víictor Hugo, et al. “Metodología Para La Generación de Mapas de Riesgo Por Inundación En Zonas Urbanas.” Tecnología y Ciencias Del Agua, vol. 7, no. 5, Instituto Mexicano de Tecnología del Agua, 2016, pp. 33-55, http://www.scielo.org.mx/scielo.php?pid=S2007-24222016000500033\&script=sci_arttext.

Amade, Benedict, et al. "Project Cost Contingency in the Nigerian Construction Industry." International Journal of Research in Management Science and Technology, vol. 2, no. 2, 2013, pp. 9-21.

AMRAE. The Risk Manager Framework. 2013

http://www.amrae.fr/sites/default/files/fichiers_upload/RiskManagerFramework_AMRAE_2013_0.pdf.

ANRA. Risk Management Standards and ISO 31000. ANRA Position Paper. 2011 http://www.strategicagroup.com/includes/pdf/Anra_Position_Paper.pdf. 
Aven, Terje. "Reflections on the Use of Conceptual Research in Risk Analysis." Risk Analysis, vol. 38, no. 11, Wiley Online Library, Nov. 2018, pp. 2415-2423, doi:10.1111/risa.13139.

Bello, Wasiu Adeniran, and Koleola Tunwase Odusami. "The Practice of Contingency Allocation in Construction Projects in Nigeria." The Construction and Building Research, edited by RICS COBRA, Royal Institution of Chartered Surveyors, 2008, pp. 1-15.

Bouayed, Zakia. "Using Monte Carlo Simulation to Mitigate the Risk of Project Cost Overruns." International Journal of Safety and Security Engineering, vol. 6, no. 2, WIT Press, 2016, pp. 293-300, doi:10.2495/SAFE-V6-N2-293-300.

Bromiley, Philip, et al. "Enterprise Risk Management: Review, Critique, and Research Directions.” Long Range Planning, vol. 48, no. 4, Elsevier, Apr. 2015, pp. 265-276, doi:10.2139/ssrn.2376261.

Carpio de los Pinos, Antonio José, and María de las Nieves González García. “Critical Analysis of Risk Assessment Methods Applied to Construction Works." Revista de La Construcción, vol. 16, no. 1, Pontificia Universidad Católica de Chile, 2017, pp. 104-14, doi:10.7764/RDLC.16.1.104.

CEB Risk Management Leadership Council. "A Guide to Risk Rating Criteria." Annual Executive Retreat, no. Apr 28, 2014, CEB Risk Management Leadership Council, 2013, https://www.cebglobal.com/content/riskmanagement/us/en/member/assetviewer.html?referrerTitle=A Guide to Risk Rating Criteria\&filePath=/content/dam/riskmanagement/us/en/General/PDF/13/12/PRO_BRF_Risk_Ratings_final.pdf\&contentType=researchreport\&searchStr.

Cheng, Min, and Yujie Lu. "Developing a Risk Assessment Method for Complex Pipe Jacking Construction Projects." Automation in Construction, vol. 58, no. 2015, Elsevier, 2015, pp. 48-59, doi:10.1016/j.autcon.2015.07.011.

Cretu, Ovidiu, et al. "The Risk Based Estimate." Risk Management for Design and Construction., Wiley, 2011.

Deng, Fei, and Hedley Smyth. "Contingency-Based Approach to Firm Performance in Construction: Critical Review of Empirical Research." Journal of Construction Engineering and Management, vol. 139, no. 10, ASCE, 2013, p. 04013004, doi:10.1061/(ASCE)CO.19437862.0000738

Diekmann, James E. "Probabilistic Estimating: Mathematics and Applications." Journal of Construction Engineering and Management, vol. 109, no. 3, American Society of Civil Engineers, 1983, pp. 297-308, doi:10.1061/(ASCE)0733-9364(1983)109:3(297).

EcoDa/IFC. A Guide to Corporate Governance Practices in the European Union. 2015,

http://ecoda.org/uploads/media/A_Guide_to_Corporate_Governance_Practices_of_the_European_Union_-_IFC_ecoDa_01.pdf.

EY. Turning Risk into Results. 2013, http://www.ey.com/Publication/vwLUAssets/Turning_risk_into_results/\$FILE/Turning risk into results_AU1082_1 Feb 2012.pdf.

Fernández Sánchez, Gonzalo. “Propuesta de Modelo Para La Evaluación de La Sostenibilidad En La Dirección Integrada de Proyectos de Ingeniería Civil." Universidad Politécnica de Madrid, Universidad Politécnica de Madrid, 2010, http://oa.upm.es/5524/\%0A.

Hamid, Razali Abdul, and Fabi Jonathan Kehinde. "Choosing an Appropriate Contingency Sum Estimating." Planning Malasia Journal, vol. 15, no. 1, 2017, pp. 13-20, doi:10.21837/pmjournal.v15.i6.217

Hoyt, Robert E., and Andre P. Liebenberg. "The Value of Enterprise Risk Management." Journal of Risk and Insurance, vol. 78, no. 4, Blackwell Publishing Inc, 2011, pp. 795-822, doi:10.1111/j.1539-6975.2011.01413.x.

Hruškovič, Pavel. "Método Para Identificar Causas de Problemas Técnicos de Proyecto Geotécnico." Universidad Politécnica de Madrid Universidad Politécnica de Madrid, 2011, http://oa.upm.es/9160/\%0A.

Institution of Civil Engineers and Institute and Faculty of Actuaries. "Risk Analysis and Management for Projects: A Strategic Framework for Managing Project Risk and Its Financial Implications." Risk Analysis and Management for Projects, edited by 3, ICE Publishing, 2004, doi:10.1680/ramp.41578.

International Organization for Standardization (ISO). "Risk Management - Guidelines." International Organization for Standardization, vol. ISO 31000:, no. 31000:2018, International Organization for Standardization, 2018, https://www.iso.org/obp/ui\#iso:std:iso:31000:ed2:v1:es.

---. “Risk Management - Risk Assessment Techniques.” International Organization for Standardization, vol. IEC 31010:, no. 31010:2019, International Organization for Standardization, June 2019, https://www.iso.org/standard/72140.html.

Jung, Ji Hyun, et al. "The Computer-Based Contingency Estimation through Analysis Cost Overrun Risk of Public Construction Project." KSCE Journal of Civil Engineering, vol. 20, no. 4, Springer, 2016, pp. 1119-30, doi:10.1007/s12205-015-0184-8.

Lam, Terence Y. M., and Njavwa Siwingwa. "Risk Management and Contingency Sum of Construction Projects." Journal of Financial Management of Property and Construction, vol. 22, no. 3, EmeraldInsight, 2017, pp. 237-251, doi:10.1108/JFMPC-10-2016-0047.

Leceta Ostolaza, Ainara. "Consideraciones y Recomendaciones Para El Diseño de Estructuras Bajo Amenaza de Tsunamis." Universidad Politécnica de Madrid, Universidad Politécnica de Madrid, 2014, http://oa.upm.es/31217/\%0A.

Lhee, Sang Choon. "Finding Significant Factors to Affect Cost Contingency on Construction Projects Using ANOVA Statistical Method." Architectural Research, vol. 16, no. 2, Architectural Institute of Korea, 2014, pp. 75-80, doi:10.5659/aikar.2014.16.2.75.

Likert, Rensis. "A Technique for the Measurement of Attitudes." Archives of Psychology, vol. 22, no. 140, Archives of Psychology, 1932, pp. 21-55, https://legacy.voteview.com/pdf/Likert_1932.pdf. 
Mantovani, Guido Max, et al. "Toward an Integrated Rating Methodology for Corporate Risk Detection." Journal of Business Economics and Finance, vol. 3, no. 1, PressAcademia, 2014, pp. 18-49, http://www.pressacademia.org/archives/jbef/v3/i1/2.pdf.

Meulbroek, Lisa K. Integrated Risk Management for the Firm: A Senior Manager's Guide. Edited by Harvard Business School, Harvard Business School, 2002, doi:10.2139/ssrn.301331.

Mishra, Surabhi, and Brajesh Mishra. "A Study on Risk Factors Involved in the Construction Projects." International Journal of Innovative Research in Science, Engineering and Technology, vol. 5, no. 2, Feb. 2016, pp. 1190-96, doi:10.15680/IJIRSET.2016.0502005.

Murakami, Michio, et al. "New 'Loss of Happy Life Expectancy' Indicator and Its Use in Risk Comparison after Fukushima Disaster." Science of the Total Environment, vol. 615, Elsevier, Feb. 2018, pp. 1527-1534, doi:10.1016/j.scitotenv.2017.09.132.

Okan, Yasmina, et al. "Designing Graphs That Promote Both Risk Understanding and Behavior Change." Risk Analysis, vol. 38, no. 5, Wiley Online Library, 2018, pp. 929-946, doi:10.1111/risa.12895.

Orojloo, Mehdi, et al. "Developing an Integrated Risk Management Framework for Agricultural Water Conveyance and Distribution Systems within Fuzzy Decision Making Approaches." Science of the Total Environment, vol. 627, Elsevier, June 2018, pp. 1363-1376, doi:10.1016/j.scitotenv.2018.01.324.

Pérez Soriano, Laura Illeana. "Seguridad Estructural Para Construcciones En Zonas Inundables. Criterio Diseño. Soluciones de Minoración Del Riesgo de Fallo." Universidad Politécnica de Madrid, Universidad Politécnica de Madrid, 2014, http://oa.upm.es/23386/.

Raftery, John. Risk Analysis in Project Management. Spon Press, 1994.

Renault, Berenger Y., and Justus N. Agumba. "Risk Management in the Construction Industry: A New Literature Review." MATEC Web of Conferences, vol. 66, no. 2016, EDP Sciences, 2016, p. 00008, doi:10.1051/matecconf/20166600008.

Rezaie, Kamran, et al. "Using Extended Monte Carlo Simulation Method for the Improvement of Risk Management: Consideration of Relationships between Uncertainties." Applied Mathematics and Computation, vol. 190, no. 2, Elsevier, 2007, pp. 1492-1501, doi:10.1016/j.amc.2007.02.038.

Rodney, E., et al. "An Integrated Management Approach of the Project and Project Risks." IFAC-PapersOnLine, vol. 48, no. 3, Elsevier, 2015, pp. 535-540, doi:10.1016/j.ifacol.2015.06.136.

Samantra, Chitrasen, et al. "A Risk-Based Decision Support Framework for Selection of Appropriate Safety Measure System for Underground Coal Mines." International Journal of Injury Control and Safety Promotion, vol. 24, no. 1, Taylor \& Francis, Aug. 2017, pp. 5468, doi:10.1080/17457300.2015.1061561.

---. "Fuzzy Based Risk Assessment Module for Metropolitan Construction Project: An Empirical Study." Engineering Applications of Artificial Intelligence, vol. 65, no. 2007, Elsevier, 2017, pp. 449-64, doi:10.1016/j.engappai.2017.04.019.

Sanchez-Cazorla, Álvaro, et al. “Risk Identification in Megaprojects as a Crucial Phase of Risk Management: A Literature Review.” Project Management Journal, vol. 47, no. 6, SAGE Publications, Dec. 2016, pp. 75-93, doi:10.1177/875697281604700606.

Schuyler, John. Risk and Decision Analysis in Projects. Project Management Institute, Inc., 2001.

Serpella, Alfredo Federico, et al. "Risk Management in Construction Projects: A Knowledge-Based Approach." Procedia - Social and Behavioral Sciences, vol. 119, Elsevier, 2014, pp. 653-62, doi:0.1016/j.sbspro.2014.03.073.

Shen, Qiyu, et al. "Railway Risk Assessment of the EPC General Contract in Ethiopia Based on the Improved Fuzzy Comprehensive Evaluation Method." ICCREM 2016, edited by ASCE, ASCE, 2018, pp. 1376-1387, doi:doi:10.1061/9780784480274.169.

Tanner, Peter, and Ramon Hingorani. “Acceptable Risks to Persons Associated with Building Structures." Structural Concrete, vol. 16, no. 3 , 2015, pp. 314-22, doi:10.1002/suco.201500012.

Tarantino-Curseri, Salvatore. “Una Breve Pincelada Sobre Algunas Áreas Del Saber Necesarias Para Una Negociación Exitosa." Suma de Negocios, vol. 8, no. 17, Elsevier, 2017, pp. 63-78, doi:10.1016/j.sumneg.2016.07.001.

Taroun, Abdulmaten. "Towards a Better Modelling and Assessment of Construction Risk: Insights from a Literature Review." International Journal of Project Management, vol. 32, no. 1, Elsevier, 2014, pp. 101-115, doi:10.1016/j.ijproman.2013.03.004.

Thamhain, Hans J. "Managing Risks in Complex Projects." Project Management Journal, vol. 44, no. 2, Wiley Subscription Services, Inc., A Wiley Company, 2013, pp. 20-35, doi:10.1002/pmj.21325.

The Institute of Internal Auditors. IIA Position Paper: TheThree Lines of Defense in Effective Risk Management and Control. no. January, The Institute of Internal auditors, 2013, https://na.theiia.org/standards-guidance/Public Documents/PP The Three Lines of Defense in Effective Risk Management and Control.pdf.

Tóth, Tamás, and Zoltán Sebestyén. "Integrated Risk Management Process for Building Projects.” Procedia Engineering, vol. 85, no. 2014, Elsevier, 2014, pp. 510-519, doi:10.1016/j.proeng.2014.10.578.

Touran, Ali, and Edward P. Wiser. "Monte Carlo Technique with Correlated Random Variables." Journal of Construction Engineering and Management, vol. 118, no. 2, American Society of Civil Engineers, 1992, pp. 258-272, doi:10.1061/(ASCE)0733-9364(1992)118:2(258).

Tsiga, Zakari, et al. “Implementation of a Risk Management Simulation Tool.” Procedia Computer Science, vol. 121, no. 2017, Elsevier, 2017, pp. 218-223, doi:10.1016/j.procs.2017.11.030. 
Van Niekerk, Mariette, and James Bekker. "Developing a Tool for Project Contingency Estimation in a Large Portfolio of Construction Projects." South African Journal of Industrial Engineering, vol. 25, no. 3, 2014, pp. 96-111,

http://www.scopus.com/inward/record.url?eid=2-s2.0-84922012224\&partnerID=tZOtx3y1.

Vegas-Fernández, Fernando. “Factor de Visibilidad. Nuevo Indicador Para La Evaluación Cuantitativa de Riesgos.” Universidad Politécnica de Madrid, edited by Universidad Politécnica de Madrid, Universidad Politécnica de Madrid, July 2019, doi:10.20868/UPM.thesis.56394.

---. "Gestión de Riesgos." XII Jornadas Valencianas de Dirección de Proyectos, PMI Valencia Spain Chapter, 2015, pp. 35-45, http://pmivalencia.org/pmi2018/index.php/noticias-y-eventos/noticias/260-resumen-de-las-xii-jornadas-valencianas-de-direccion-de-proyectos.

---. "Sistema de Información de Riesgos: Factor de Visibilidad." El Profesional de La Informacion, vol. 26, no. 6, Oct. 2017, pp. 1065-1075, doi:10.3145/epi.2017.nov.06.

Vegas-Fernández, Fernando, and Fernando Rodríguez-López. "Methodology for Determining the Most Severe Risks of a Construction Project and Identification of Risky Projects." Revista de La Construcción, vol. 17, no. 3, Universidad Católica de Chile, Dec. 2018, pp. 423435, doi:10.7764/RDLC.17.3.423.

Venkatraman, S., and Vasudevan Ramasamy. "A Study on Risk Assessment for Implementing Innovative Ideas in Construction Sector." International Journal of Pure and Applied Mathematics, vol. 116, no. 13, Academic Publications, 2017, pp. 603-608, https://www.researchgate.net/publication/321572888_A_STUDY_ON_RISK_ASSESSMENT_FOR_IMPLEMENTING_INNOVATIVE_IDEAS_IN_ CONSTRUCTION_SECTOR.

West, Camilla, et al. "Why Do Residential Recycled Water Schemes Fail? A Comprehensive Review of Risk Factors and Impact on Objectives." Water Research, vol. 102, Elsevier, June 2016, pp. 271-281, doi:10.1016/j.watres.2016.06.044.

Zio, Enrico. "The Future of Risk Assessment." Reliability Engineering \& System Safety, vol. 177, Elsevier, 2018, pp. 176-190, doi:10.1016/j.ress.2018.04.020.

Zou, Patrick X. W., et al. "Understanding and Improving Your Risk Management Capability: Assessment Model for Construction Organizations." Journal of Construction Engineering and Management, vol. 136, no. 8, Aug. 2010, pp. 854-63, doi:10.1061/(asce)co.19437862.0000175

Zurich Insurance Group. Tomorrow's Risk Leadership: Delivering Risk Resilience and Business Performance. no. Apr. 27, 2016, 2015 http://knowledge.zurich.com/risk-interconnectivity/tomorrows-risk-leadership-delivering-risk-resilience-and-business-performance/. 